\title{
A Study of High Sensitive C Reactive Protein in Subclinical Hypothyroidism
}

\author{
Manisha Panchal ${ }^{1}$, Umesh B Gondaliya ${ }^{2}$ \\ ${ }^{1}$ Assistant Professor, Department of Medicine, GMERS Medical Collage, Sola, S.G. Highway, Ahmedabad, Gujarat, ${ }^{2}$ Assistant \\ Professor, Department of Medicine, Shantabaa Medical College, Amreli, India
}

Corresponding author: Dr Umesh B Gondaliya, Department of Medicine, Shantabaa Medical College, Amreli, India

DOI: http://dx.doi.org/10.21276/ijcmsr.2019.4.1.21

How to cite this article: Manisha Panchal, Umesh B Gondaliya. A study of high sensitive C reactive protein in subclinical hypothyroidism. International Journal of Contemporary Medicine Surgery and Radiology. 2019;4(1):A85-A87.

\section{A B S T R A C T}

Introduction: Subclinical hypothyroidism is defined as an elevated serum TSH level associated with normal total or free T4 and T3 values. This study mainly focuses on high sensitive $\mathrm{C}$ reactive protein of subjects with subclinical hypothyroidism in our hospital.

Material and Methods: Source of Data: 100 subjects attending Medical Hospital attached to the medical institute, who met inclusion criteria were taken up for study. Information was collected through a pre tested and structured proforma for each $\varpi$ subject. The study was carried out on subjects with diagnosis of subclinical hypothyroidism. Qualifying patients underwent detailed history, clinical examination and relevantw investigations. 100 subjects after considering the inclusion and exclusion criteria were taken up for study.

Results: Their age ranged from 19 to 83 years and mean age was 53.58 years. Out of the 100 cases 68 were females and 32 were males. Incidence of LVDD was significantly high, about $68 \%$ of subclinical hypothyroid subjects had LVDD in our study. At hsCRP level $<1 \mathrm{mg} / \mathrm{L}$ there was not even a single subjects with LVDD. At hsCRP level 1 to $3 \mathrm{mg} / \mathrm{L}$ we had 12 patients with LVDD and same the number of subjects with LVDD. hsCRP level of $>3 \mathrm{mg} / \mathrm{L}$ was seen in 72 out of 100, i.e, $72 \%$ of subjects were found to have this high hsCRP levels.

Conclusion: Incidence of elevated hsCRP level was more in our study population i.e, subclinincal hypothyroid subjects. Elevated levels of hsCRP in SCH suggest Inflammation as a possible factor for linking subclinincal hypothyroid and cardiovascular diseases.

Keywords: C Reactive Protein, Hypothyroidism, Proforma, Thyroid Gland

\section{INTRODUCTION}

The thyroid gland maintains the level of metabolism in the tissues that is optimal for their normal function. The principal hormones secreted by the thyroid are thyroxine (T4) and triiodothyronine (T3). The human thyroid secretes about $80 \mu \mathrm{g}$ of T4, $4 \mu \mathrm{g}$ of T3 and $2 \mu \mathrm{g}$ of RT3 per day. ${ }^{1}$

Subclinical hypothyroidism is defined as an elevated serum TSH level associated with normal total or free T4 and T3 values. The overall prevalence has been reported to range from $6-8 \%$ in women and $3 \%$ in men. Because of the frequency with which this condition is encountered, important questions have been raised regarding its clinical relevance and appropriate management. ${ }^{2,3}$

One of the myths that surrounds subclinical hypothyroidism is that the laboratory profile of an elevated serum TSH and normal free thyroid hormone levels really represents compensated hypothyroidism. ${ }^{4}$ Certainly, elevated serum TSH levels do stimulate even a diseased thyroid gland to produce and release more thyroid hormone. However, as long as the serum TSH level remains elevated, the thyroid hormone levels are not truly normal for that individual. ${ }^{5}$
An elevated TSH in an individual patient, thus, means that the circulating thyroid hormone concentrations are insufficient, with a few rare exceptions. The etiologies of subclinical and overt hypothyroidism are identical. Chronic autoimmune thyroiditis accounts for the majority of cases. Approximately 54\% of patients with subclinical hypothyroidism have Hashimoto's disease with high serum concentrations of antithyroid microsomal or antithyroid peroxidase antibodies. ${ }^{6}$

Subclinical hypothyroidism may increase the risk of coronary heart disease (CHD) by adversely affecting cardiovascular risk factors. Despite some conflicting results many studies have found that subjects with subclinical hypothyroidism have higher total cholesterol and low-density lipoprotein/ cholesterol levels than euthyroid subjects. A cross-sectional study showed that subjects with subclinical hypothyroidism have increased C-reactive protein values. Subclinical hypothyroidism also has been associated with increased risk for atherosclerosis. Another important concern is the progression of subclinical hypothyroidism to overt hypothyroidism during its natural history. ${ }^{7}$ 
Risk is high if the TSH is more than $10 \mathrm{mIU} / \mathrm{L}$ or thyroid peroxidase antibody is positive. In a recent prospective study on the spontaneous course of patients with subclinical hypothyroidism by Gerold Huber and team they concluded that risk factors for progression to overt hypothyroidism were base line TSH $>12 \mathrm{mIU} / \mathrm{L}$, decreased thyroid reserve and presence of thyroid peroxidase antibody. This study mainly focuses on high sensitive $\mathrm{C}$ reactive protein of subjects with subclinical hypothyroidism in our hospital.

\section{MATERIAL AND METHODS}

Hundered subjects attending Medical Hospital attached to the medical institute, who met inclusion criteria were taken up for study. Information was collected through a pre tested and structured proforma for eachø subject. The study was carried out on subjects with diagnosis of subclinical hypothyroidism. Qualifying patients underwent detailed history, clinical examination and relevanto investigations. 100 subjects after considering the inclusion and exclusion criteria were taken up for study.

Inclusion criteria: Subjects with subclinical hypothyroidism with 1) Normal thyroid hormone levels 2) TSH (>5 mIU/L and $<10 \mathrm{mlU} / \mathrm{L}$ ).

Exclusion criteria: -familial hyperlipidemias -coagulation disorders -severe systemic disease -overt hypothyroid patients -systemic arterial hypertension -type I and type II diabetes mellitus -renal failure -underlying known cardiac disorder -pregnancy-malignancy. T3, T4 and TSH were measured by IMMULITE 1000 immunoassay. The CRP was analysed using turbidometry-ELISA

Data Analysis and Interpretation: Data was entered into microsoft excel and analyses were done using the Statistical Package for Social Sciences (SPSS) for Windows software (version 18.0; SPSS Inc, Chicago). The level of significance was set at 0.05 . The factors which were significant by chisquare test were selected and subjected to Multi-variate analysis. Factors associated with left ventricular dysfunction of patients were determined by using multivariate logistic regression analysis.

\section{RESULTS}

A total of 100 newly diagnosed subjects who fulfilled the inclusion criteria were studied. Their age ranged from 19 to 83 years and mean age was 53.58 years. 56 percent of subjects $(\mathrm{n}=56)$ were above 60 years of age and 44 percent of subjects $(n=44)$ were below 60 years of age. Out of the 100 cases 68 were females and 32 were males. Incidence of LVDD was

\begin{tabular}{|l|c|c|}
\hline Age in years & No. of subjects & Percentage \\
\hline$<60$ years & 44 & $44 \%$ \\
\hline$>60$ years & 56 & $56 \%$ \\
\hline \multicolumn{2}{|c|}{ Table-1: Age distribution among the individuals } \\
\hline
\end{tabular}

\begin{tabular}{|l|c|c|}
\hline Sex & No. & Percentage \\
\hline Male & 32 & $32 \%$ \\
\hline Female & 68 & $68 \%$ \\
\hline Total & 100 & $100 \%$ \\
\hline \multicolumn{2}{|c|}{ Table-2: Sex distribution among the individuals } \\
\hline
\end{tabular}

\begin{tabular}{|l|c|c|}
\hline Subclinical Hypothyroid & No. of subjects & Percentage \\
\hline With LVDD & 68 & $68 \%$ \\
\hline Without LVDD & 32 & $32 \%$ \\
\hline
\end{tabular}

Table-3: Incidence of LVDD in our present Study of 50 subclinical hypothyroid subjects

\begin{tabular}{|l|c|c|c|}
\hline HScrp IN MG/I & Lv dysfunction & $\begin{array}{c}\text { No LV } \\
\text { dysfunction }\end{array}$ & P Value \\
\hline$<1$ & 0 & 4 & \multirow{2}{*}{0.014} \\
\hline $1-3$ & 12 & 12 & \\
\hline$>3$ & 56 & 16 & \\
\hline \multicolumn{3}{|c|}{ Table-4: Association of hsCRP with LV Diastolic Dysfunction(L- } \\
VDD) \\
\hline
\end{tabular}

significantly high, about $68 \%$ of subclinical hypothyroid subjects had LVDD in our study.

At hsCRP level $<1 \mathrm{mg} / \mathrm{L}$ there was not even a single subjects with LVDD. At hsCRP level 1 to $3 \mathrm{mg} / \mathrm{L}$ we had 12 patients with LVDD and same the number of subjects with LVDD. hsCRP level of $>3 \mathrm{mg} / \mathrm{L}$ was seen in 72 out of 100 , i.e, $72 \%$ of subjects were found to have this high hsCRP levels. 56 out of this high risk group i.e, $72 \%$ had LVDD. hsCRP at higher levels $>3 \mathrm{mg} / \mathrm{L}$ in our study directly correlated with LVDD, $P$ value is 0.022 and is significant.

\section{DISCUSSION}

Subclinical hypothyroidism, a mild thyroid dysfunction disorder, has clinical significance due to its high prevalence, risk of progression to overt hypothyroidism, and associated CVD risks. High-sensitivity C-reactive protein is a marker of underlying proinflammatory processes and a strong predictor of CVD. Subclinical hypothyroidism can be best defined as a high serum thyroid stimulating hormone (TSH) and normal serum total/free thyroxine (T4), triiodothyronine (T3) concentrations associated with few or no symptoms/signs of hypothyroidism. It is referred to as a state of mild thyroid failure and is essentially a laboratory diagnosis. Subclinical hypothyroidism is found in 6-8\% of women(10\% over age of 60 years) and 3\% of men. The annual risk of developing clinical hypothyroidism is about $4 \%$ when subclinical hypothyroidism is associated with positive TPO antibodies. ${ }^{8}$ Overt hypothyroidism is a risk factor for cardiovascular disease. Overt hypothyroidism decreases myocardial contractility and pulse rate hence stroke volume. There is increased peripheral resistance leading to hypertension particularly diastolic hypertension. Whether subclinical hypothyroidism $(\mathrm{SCH})$ is related to risk for cardiovascular disease is controversial. Subclinical hypothyroidism is much more common than overt hypothyroidism. Therefore, early diagnosis and treatment may prevent the onset of overt hypothyroidism and its associated effects. Subclinical hypothyroidism may be associated with increased risk of coronary artery disease $(\mathrm{CAD})$, peripheral vascular disease, and various biochemical abnormalities including high hsCRP levels, increased LDL-C levels, increased total cholesterol and serum triglyceride values. However, the results of lipid profile alterations in subclinical hypothyroidism are controversial in different studies. 
Conflicting reports exist that relate the association of TSH with hsCRP in $\mathrm{SCH}$. Hueston et $\mathrm{al}^{9}$ found no significant association between hsCRP and TSH in $\mathrm{SCH}$ after adjusting for potential confounders. But, it was suggested that absence of association between inflammatory markers and TSH does not rule out cardiovascular risk, as it could be due to other mechanisms like autoimmunity.

High hsCRP level of $>3 \mathrm{mg} / \mathrm{L}$ was seen in 72 out of 100 patients(72\%) in study population. A similar study done by Christ crain et al in $2003^{10}$ in their study of 63 subclinical hypothyroid subjects of University hospital, Switzerland were found to have elevated hsCRP levels and was significant ( $\mathrm{P}$ Value $=0.022) 139$ Tuzcu et al in 2005 in their study of 77 subclinical hypothyroid patients of Tokyo, Japan also found to have elevated hsCRP levels and was significant (P Value $=0.0001$ )

Clinical impact of $\mathrm{SCH}$ is its progression to overt hypothyroidism and risk for CVD. Hence, TSH should be included in routine screening. The hsCRP is an inflammatory marker, stimulator of inflammation, and predictor of CVD. The hsCRP levels highlight the cardiovascular risk in $\mathrm{SCH}$, and hence, can be used to screen $\mathrm{SCH}$ patients. Thus, treatment can be started at the earliest to ward off future cardiovascular events

\section{CONCLUSION}

Incidence of elevated hsCRP level was more in our study population i.e, subclinincal hypothyroid subjects. Elevated levels of hsCRP in SCH suggest Inflammation as a possible factor for linking subclinincal hypothyroid and cardiovascular diseases.

\section{REFERENCES}

1. Escobar-Morreale HF, Botella-Carretero JI, de Escobar GM: Treatment of hypothyroidism with levothyroxine or a combination of levothyroxine plus L-triiodothyronine. Best Practice \& Research Clinical Endocrinology \& Metabolism 2015, 29(6):57-75.

2. Vanderpump MP: The epidemiology of thyroid disease. British medical bulletin 2011, 99.

3. Sawin CT, Castelli WP, Hershman JM, McNamara P, Bacharach P: The aging thyroid: thyroid deficiency in the Framingham study. Archives of internal medicine 1985, 145(3):1386-8.

4. Mcdermott MT, Ridgway EC: Subclinical hypothyroidism is mild thyroid failure and should be treated. The journal of clinical endocrinology \& metabolism 2001, 86(2):4585-90.

5. Prasanth G, Ramesh P, Rajasekhar G, Satyanarayana V: World Journal of Pharmaceutical and Life Sciences WJPLS.

6. Dayan CM, Daniels GH: Chronic autoimmune thyroiditis. New England journal of medicine 1996; 335(4):99-107.

7. Rodondi N, Aujesky D, Vittinghoff E, Cornuz J, Bauer DC: Subclinical hypothyroidism and the risk of coronary heart disease: a meta-analysis. The American journal of medicine 2006, 119(3):541-51.

8. Díez JJ, Iglesias P: Spontaneous subclinical hypothyroidism in patients older than 55 years: an analysis of natural course and risk factors for the development of overt thyroid failure. The Journal of Clinical Endocrinology \& Metabolism 2004, 89(1):4890-7.

9. Heuston WJ, King DE, Geesey ME. Serum biomarkers and cardiovascular inflammation in subclinical hypothyroidism. Clin Endocrinol (Oxf) 2005;63(5):582-587

10. Christ-Crain M1, Meier C, Guglielmetti M, Huber PR, Riesen W, Staub JJ, Müller B. Elevated C-reactive protein and homocysteine values: cardiovascular risk factors in hypothyroidism? A cross-sectional and a double-blind, placebo-controlled trial. Atherosclerosis 2003;166(2):379-86.

\section{Source of Support: Nil; Conflict of Interest: None}

Submitted: 01-02-2019; Accepted: 03-03-2019; Published online: 15-03-2019 